\title{
Effect of untreated carotid artery stenosis at the time of isolated coronary artery bypass grafting
}

\author{
Nicholas R. Hess, MD, ${ }^{a}$ Arman Killic, MD, ${ }^{\mathrm{a}, \mathrm{b}}$ Derek R. Serna-Gallegos, MD, ${ }^{\mathrm{a}, \mathrm{b}}$ Forozan Navid, MD, ${ }^{\mathrm{a}, \mathrm{b}}$
} Yisi Wang, MPH, ${ }^{\mathrm{a}}$ Floyd Thoma, BS, ${ }^{\mathrm{a}}$ and Ibrahim Sultan, $\mathrm{MD}^{\mathrm{a}, \mathrm{b}}$

\section{ABSTRACT}

Background: Severe carotid artery stenosis (sCAS) is frequently discovered at the time of evaluation for coronary arterial revascularization. However, there has been controversy regarding the optimal management of sCAS. This study evaluated the potential effects of untreated sCAS at time of coronary artery bypass grafting (CABG) in contemporary practice.

Methods: This was a retrospective study from a multihospital healthcare system including patients undergoing isolated CABG between 2011 and 2018. Patients were stratified by the presence of sCAS ( $\geq 80 \%$ stenosis) in at least 1 carotid artery. Perioperative and 5-year stroke were compared, and multivariable analysis was used to identify risk-adjusted predictors of stroke and mortality.

Results: A total of 5475 patients were included, 459 (8.4\%) with sCAS and 5016 (91.6\%) without SCAS. Patients with SCAS experienced more frequent perioperative stroke $(4.4 \%$ vs $1.2 \% ; P<.001)$, with most attributable to ischemic or embolic etiologies. The median duration of follow-up was 4.6 years (interquartile range, 3.06.5 years). One-year and 5 -year survival were both lower in patients with SCAS $(P<.001)$. In multivariable analysis, sCAS was associated with increased riskadjusted hazard for both mortality (hazard ratio [HR], 1.28; $95 \%$ confidence interval $[\mathrm{Cl}], 1.02-1.60 ; P=.030)$ and stroke $(\mathrm{HR}, 1.76 ; 95 \% \mathrm{Cl}, 1.20-2.59 ; P=.004)$. The strongest risk-adjusted predictor for stroke was a previous history of stroke (HR, 2.51; $95 \% \mathrm{Cl}, 1.77-3.55 ; P<.001$ ).

Conclusions: This contemporary analysis of CABG procedures reveals that concurrent SCAS continues to confer a significant stroke risk, especially in those with history of previous stroke. Although whether sCAS lesions are responsible for most strokes is unclear, they likely serve as a surrogate for other stroke risk factors. (JTCVS Open 2021;7:182-90)

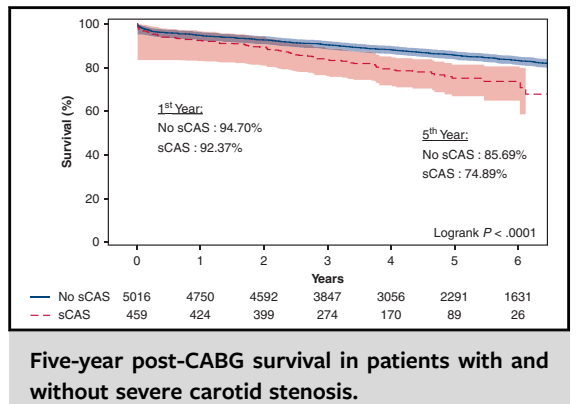

without severe carotid stenosis.

CENTRAL MESSAGE

Untreated severe carotid artery stenosis (sCAS) confers a significant stroke risk at the time of coronary artery bypass grafting surgery. Although whether sCAS lesions are responsible for most strokes is unclear, they likely serve as a surrogate for other stroke risk factors.

\section{PERSPECTIVE}

This study highlights the strong association of severe carotid artery stenosis with postoperative stroke risk following isolated coronary artery bypass grafting surgery, although the majority of these events are not likely attributable to the lesions themselves. Routine carotid imaging may allow for risk stratification but is unlikely to prevent the majority of strokes that occur.

See Commentaries on pages 191 and 193.
From the ${ }^{\mathrm{a} D i v i s i o n}$ of Cardiac Surgery, University of Pittsburgh and ${ }^{\mathrm{b}} \mathrm{Heart}$ and Vascular Institute, University of Pittsburgh Medical Center, Pittsburgh, Pa.

Received for publication Oct 28, 2020; accepted for publication July 7, 2021; available ahead of print July 28, 2021 .

Address for reprints: Ibrahim Sultan, MD, Division of Cardiac Surgery, Department of Cardiothoracic Surgery, Center for Thoracic Aortic Disease, University of Pittsburgh, Heart and Vascular Institute, University of Pittsburgh Medical Center, 5200 Centre Ave, Suite 715, Pittsburgh, PA 15232 (E-mail: sultani@upmc.edu). 2666-2736

Copyright (C) 2021 The Author(s). Published by Elsevier Inc. on behalf of The American Association for Thoracic Surgery. This is an open access article under the CC BY-NC-ND license (http://creativecommons.org/licenses/by-nc-nd/4.0/).

https://doi.org/10.1016/j.xjon.2021.07.001
Severe carotid arterial stenosis (sCAS) often develops concurrently with coronary artery disease, and it is frequently discovered during the preoperative workup for coronary artery bypass grafting (CABG). ${ }^{1,2}$ sCAS has long been described as a risk factor for perioperative stroke following $\mathrm{CABG}{ }^{3}{ }^{3}$ This increase in stroke risk is thought to derive from 2 factors. First, embolic strokes can originate from unstable plaques within the vascular system, ${ }^{4}$ and regions of sCAS can be a source of unstable plaque rupture and/or thrombus formation. Second, ischemic strokes 


\section{Abbreviations and Acronyms \\ $\mathrm{CABG}=$ coronary artery bypass grafting \\ $\mathrm{CVA}=$ cerebrovascular accident \\ MAP $=$ mean arterial pressure \\ sCAS $=$ severe carotid artery stenosis \\ STS $=$ Society of Thoracic Surgeons}

secondary to brain malperfusion are often incited by periods of perioperative hypotension, and these states may be exacerbated by regions of significant stenosis. ${ }^{5-7}$

Presence of concurrent sCAS and coronary disease have posed a challenge to surgeons regarding the optimal treatment strategy. Historical studies have described higher rates of morbidity and/or mortality when revascularization of the coronary arteries and revascularization of the carotid arteries are performed simultaneously. ${ }^{2,6,8}$ For this reason, many centers have opted to treat the more symptomatic lesion first, with staged intervention of the other lesion at a later time. With carotid screening often performed during initial CABG evaluation, ${ }^{1}$ the presence of disease is often known at the time of coronary revascularization. Measures to reduce stroke are often used by cardiac surgeons at the time of CABG in patients with known sCAS. These include higher intraoperative blood pressure and cardiopulmonary bypass perfusion pressure goals, as well as strict blood pressure control in the postoperative period. With advancements in perioperative care, it is not well known whether concurrent sCAS continues to confer a significant stroke risk during $\mathrm{CABG}$ procedures. This study aimed to investigate the prevalence of concurrent sCAS at time of CABG, as well as its potential impacts on perioperative and long-term stroke in contemporary healthcare practice.

\section{METHODS}

\section{Study Design}

This study was a retrospective analysis that used pooled institutional data from a large, multihospital healthcare system. Preoperative baseline characteristics and comorbidities, operative details, and longitudinal clinical outcomes were extracted from our institutional electronic health records. All patient identifiers were removed from the dataset.

\section{Study Ethics}

This study was approved by the Institutional Review Board at the University of Pittsburgh (MOD18120143-003, approved March 9, 2020). Patient consent was waived owing to the study's retrospective nature.

\section{Definitions}

Severe CAS was defined at $\geq 80 \%$ stenosis in at least 1 carotid artery.

\section{Inclusion Criteria}

This study included adults (age $\geq 18$ years) who underwent primary isolated CABG at a multihospital health system between January 2011 and June 2018. Patients were stratified on whether or not preoperative sCAS was detected on routine carotid ultrasound screening.

\section{Exclusion Criteria}

Patients undergoing redo surgery or underwent multiple procedures in addition to $\mathrm{CABG}$ were excluded. Patients who underwent previous carotid artery intervention (carotid endarterectomy or stenting) were also excluded.

\section{Outcomes}

The primary outcomes of this study were rates of perioperative and 5 -year stroke. Secondary outcomes included perioperative mortality and 5 -year survival. Other outcomes investigated were rates of reoperation and other complications, including renal failure, pneumonia, and wound infection. We also investigated freedom from hospital readmission, as well as risk-adjusted predictors of postoperative stroke and mortality via multivariable modeling.

\section{Subanalysis}

A subanalysis was conducted to assess associations with intraoperative hemodynamics and postoperative stroke. In all patients with available intraoperative records, all intraoperative mean arterial pressures (MAP) were recorded. For each patient, both the lowest and median intraoperative MAPs were determined, and these were compared across cohorts both with and without sCAS, as well as those who experienced stroke and those who did not. Lowest and median MAP were also modeled in a univariable analysis to determine associations with stroke.

\section{Statistical Analysis}

Continuous data are presented as mean \pm standard deviation for Gaussian variables or median (interquartile range [IQR]) for nonGaussian variables, and categorical data are presented as number (percentage). Normality was assessed using the Kolmogorov-Smirnov test. Normally distributed continuous data and categorical data were compared with Pearson's $\chi^{2}$ test or Fisher's exact test when $25 \%$ of the available data points had expected values $<5$. Non-Gaussian distributions were evaluated using the Mann-Whitney $U$ test.

Multivariable Cox proportional hazards modeling was used to model mortality and identify risk-adjusted predictors of this outcome. Competing-risk methods by Fine and Gray modeling were used to model readmission for stroke. Covariables were first assessed by univariable modeling, and then backward elimination was performed, with a threshold of $P<.1$ for inclusion into the multivariable model. Finally, the lowest and median intraoperative MAPs were modeled in a univariable logistic regression to assess associations with the outcome of postoperative stroke.

\section{RESULTS \\ Baseline Patient Demographics and Operative Characteristics}

A total of 5475 patients who underwent CABG were included in the analysis, $5016(91.6 \%)$ without sCAS and $459(8.4 \%)$ with significant concurrent sCAS. Two hundred and eighty-nine patients who had prior intervention performed on the affected carotid artery (endarterectomy or stenting) before $\mathrm{CABG}$ were excluded. Among the patients with sCAS, $439(95.6 \%)$ were found to have unilateral severe lesions, and $20(4.4 \%)$ had bilateral lesions. The patients with sCAS were older, more likely female, and had a higher prevalence of comorbidities such as hypertension, chronic obstructive pulmonary disease, peripheral vascular disease, congestive heart failure, and previous CVA. Both cohorts were bridged to surgery with either intravenous inotropes or intra-aortic balloon counterpulsation at similar 
TABLE 1. Baseline characteristics and operative details of unmatched cohorts of patients undergoing CABG with and without sCAS

\begin{tabular}{|c|c|c|c|}
\hline Characteristic & No $\operatorname{SAAS}(\mathrm{N}=5016)$ & $\operatorname{sCAS}(\mathbf{N}=\mathbf{4 5 9})$ & $P$ value \\
\hline Age, y, median (interquartile range) & $66.00(58.00-73.00)$ & $69.00(64.00-76.00)$ & $<.001$ \\
\hline Body mass index, $\mathrm{kg} / \mathrm{m}^{2}$, median (interquartile range) & $29.67(26.19-33.88)$ & $28.41(25.08-32.29)$ & $<.001$ \\
\hline Body surface area, $\mathrm{m}^{2}$, mean $\pm \mathrm{SD}$ & $2.07 \pm 0.26$ & $2.00 \pm 0.25$ & $<.001$ \\
\hline Female sex, n $(\%)$ & $1234(24.60)$ & $141(30.72)$ & $<.001$ \\
\hline \multicolumn{4}{|l|}{ Race, n (\%) } \\
\hline White & $4629(92.28)$ & $433(94.34)$ & .17 \\
\hline Black & $252(5.02)$ & $14(3.05)$ & \\
\hline Other & $135(2.69)$ & $12(2.61)$ & \\
\hline Diabetes mellitus, n (\%) & $2334(46.53)$ & $217(47.28)$ & .76 \\
\hline Dialysis dependency, $\mathrm{n}(\%)$ & $125(2.49)$ & $17(3.70)$ & .12 \\
\hline Chronic obstructive pulmonary disease, $\mathrm{n}(\%)$ & $1017(20.28)$ & $125(27.23)$ & $<.001$ \\
\hline Hypertension, n (\%) & $4448(88.68)$ & $425(92.59)$ & .01 \\
\hline Immunosuppression, $\mathrm{n}(\%)$ & $243(4.84)$ & $20(4.36)$ & .64 \\
\hline Family history of coronary artery disease, $\mathrm{n}(\%)$ & $1313(26.18)$ & $88(19.17)$ & $<.001$ \\
\hline Cerebrovascular disease, $\mathrm{n}(\%)$ & $610(12.16)$ & $459(100.0)$ & $<.001$ \\
\hline Peripheral vascular disease, $\mathrm{n}(\%)$ & $879(17.52)$ & $137(29.85)$ & $<.001$ \\
\hline Prior cerebrovascular accident, $\mathrm{n}(\%)$ & $300(5.98)$ & $56(12.20)$ & $<.001$ \\
\hline Prior myocardial infarction, n (\%) & $3260(64.99)$ & $312(67.97)$ & .20 \\
\hline \multicolumn{4}{|l|}{ Cardiac presentation, $\mathrm{n}(\%)$} \\
\hline Asymptomatic & 499 (9.95) & $49(10.68)$ & .08 \\
\hline Symptoms unlikely ischemia & $11(0.22)$ & $1(0.22)$ & \\
\hline Stable angina & $433(8.63)$ & $36(7.84)$ & \\
\hline Unstable angina & $2068(41.23)$ & $171(37.25)$ & \\
\hline NSTEMI & $1484(29.59)$ & $149(32.46)$ & \\
\hline STEMI & $348(6.94)$ & $25(5.45)$ & \\
\hline Symptoms equivalent to angina & $56(1.12)$ & $9(1.96)$ & \\
\hline Other & $117(2.33)$ & $19(4.14)$ & \\
\hline Congestive heart failure, $\mathrm{n}(\%)$ & $701(13.98)$ & $90(19.61)$ & $<.001$ \\
\hline \multicolumn{4}{|l|}{ NYHA class symptoms, $\mathrm{n}(\%)$} \\
\hline I & $4320(86.12)$ & $367(79.96)$ & $<.001$ \\
\hline II & $128(2.55)$ & $16(3.49)$ & \\
\hline III & $302(6.02)$ & $47(10.24)$ & \\
\hline IV & $266(5.30)$ & $29(6.32)$ & \\
\hline Cardiac arrhythmia, n (\%) & $695(13.86)$ & $80(17.43)$ & .04 \\
\hline \multicolumn{4}{|l|}{ Number of diseased vessels, $\mathrm{n}(\%)$} \\
\hline 0 & $5(0.10)$ & $0(0.00)$ & $<.001$ \\
\hline 1 & $204(4.07)$ & $3(0.65)$ & \\
\hline 2 & $1058(21.09)$ & $59(12.85)$ & \\
\hline 3 & $3741(74.58)$ & $397(86.49)$ & \\
\hline Preoperative antiplatelet, n (\%) & $4679(93.28)$ & $423(92.16)$ & .36 \\
\hline Preoperative anticoagulation, $\mathrm{n}(\%)$ & $2331(46.47)$ & $209(45.53)$ & .70 \\
\hline Intravenous inotropes, $\mathrm{n}(\%)$ & $81(1.61)$ & $6(1.31)$ & .61 \\
\hline Cardiopulmonary bypass utilization, $\mathrm{n}(\%)$ & $3597(71.71)$ & $353(76.91)$ & .02 \\
\hline Perfusion time, min, median (interquartile range) & $97.00(78.00-119.0)$ & $92.00(76.00-116.0)$ & .12 \\
\hline Cross-clamp time, min, median (interquartile range) & $68.00(52.00-87.00)$ & $63.00(48.50-84.00)$ & .01 \\
\hline
\end{tabular}


TABLE 1. Continued

\begin{tabular}{|c|c|c|c|}
\hline Characteristic & No sCAS $(N=5016)$ & $\operatorname{sCAS}(\mathrm{N}=459)$ & $P$ value \\
\hline \multicolumn{4}{|l|}{ Intra-aortic balloon pump use, $\mathrm{n}(\%)$} \\
\hline None & $4553(90.77)$ & $427(93.03)$ & .20 \\
\hline Preoperative & $359(7.16)$ & $22(4.79)$ & \\
\hline Intraoperative & $79(1.57)$ & $9(1.96)$ & \\
\hline Postoperative & $25(0.50)$ & $1(0.22)$ & \\
\hline Bilateral internal mammary artery harvest, $\mathrm{n}(\%)$ & $1467(29.25)$ & $146(31.81)$ & .25 \\
\hline Serum creatinine, mg/dL, median (interquartile range) & $1.00(0.80-1.19)$ & $1.00(0.80-1.29)$ & $<.001$ \\
\hline Total albumin, g/dL, median (interquartile range) & $3.70(3.30-3.90)$ & $3.60(3.30-3.80)$ & $<.001$ \\
\hline Total bilirubin, mg/dL, median (interquartile range) & $0.60(0.40-0.80)$ & $0.50(0.40-0.70)$ & $<.001$ \\
\hline $\begin{array}{l}\text { Left ventricular ejection fraction, } \% \text {, median } \\
\text { (interquartile range) }\end{array}$ & $55.00(43.00-58.00)$ & $53.00(40.00-60.00)$ & .74 \\
\hline \multicolumn{4}{|l|}{ Operative status, $\mathrm{n}(\%)$} \\
\hline Elective & $1585(31.60)$ & $159(34.64)$ & .03 \\
\hline Urgent & $3157(62.94)$ & $287(62.53)$ & \\
\hline Emergent & $274(5.46)$ & $13(2.83)$ & \\
\hline Complete revascularization, $\mathrm{n}(\%)$ & $4104(81.82)$ & $285(62.09)$ & $<.001$ \\
\hline STS risk of mortality, $\%$, median (interquartile range) & $1.09(0.59-2.32)$ & $2.00(0.98-3.74)$ & $<.001$ \\
\hline STS risk of stroke, $\%$, median (interquartile range) & $0.92(0.60-1.52)$ & $1.97(1.31-2.86)$ & $<.001$ \\
\hline
\end{tabular}

sCAS, Severe carotid artery disease; SD, standard deviation; NSTEMI, non-ST elevation myocardial infarction; STEMI, ST elevation myocardial infarction; NYHA, New York Heart Association; STS, Society of Thoracic Surgeons.

rates. Patients with sCAS also were less likely to undergo complete revascularization following CABG $(62.1 \%$ vs $81.8 \% ; P<.001)$ (Table 1$)$.

\section{Perioperative Outcomes and Complications}

Following revascularization, patients with sCAS experienced a higher (but not statistically significantly so) rate of perioperative mortality $(2.83 \%$ vs $1.63 \% ; P=.06)$. The sCAS cohort had a higher rate of reoperation $(7.19 \%$ vs $4.69 \% ; P=.02$ ) and a higher frequency of postoperative blood transfusion $(33.12 \%$ vs $28.49 \%, P=.04)$. The rate of postoperative stroke was higher in patients with sCAS $(4.36 \%$ vs $1.16 \% ; P<.001)$. Rates of prolonged ventilation, pneumonia, sepsis and wound infection were similar in the 2 cohorts (Table 2).

A total of 20 stroke events occurred in patients with sCAS at time of surgical revascularization. Of these, 18 events $(90.0 \%)$ occurred in patients with unilateral sCAS and 2 $(10.0 \%)$ occurred in patients with bilateral sCAS. On review of brain imaging of these stroke events, $8(40.0 \%)$ had both an etiology and affected brain distribution that could have been impacted by the patient's preexisting carotid disease.

Among the patients with 78 stroke events that occurred within this study cohort, $19(24.4 \%)$ died before hospital discharge. Nine patients $(11.5 \%)$ experienced long-term major deficits with functional dependency, and 21 patients $(26.9 \%)$ were functionally independent with persistent mild to moderate deficits. Twenty-nine patients $(37.2 \%)$ had full recovery of neurologic deficits either by hospital discharge or during postdischarge rehabilitation. The presence of sCAS was not found to have significant associations

TABLE 2. Postoperative complications following CABG unmatched patients with and without SCAS

\begin{tabular}{lccc}
\hline \multicolumn{1}{c}{ Complication } & $\begin{array}{c}\text { No sCAS } \\
(\mathbf{N}=\mathbf{5 0 1 6}),\end{array}$ & $\begin{array}{c}\text { sCAS } \\
\mathbf{n}(\mathbf{N}=\mathbf{4 5 9}),\end{array}$ & \\
$\mathbf{n}(\%)$ & $\boldsymbol{P}$ value \\
\hline Operative mortality & $82(1.63)$ & $13(2.83)$ & .06 \\
Reoperation & $235(4.69)$ & $33(7.19)$ & .02 \\
\hline Blood product transfusion & $1429(28.49)$ & $152(33.12)$ & .04 \\
Prolonged ventilation & $336(6.70)$ & $36(7.84)$ & .35 \\
Pneumonia & $121(2.41)$ & $12(2.61)$ & .79 \\
Renal failure & $115(2.29)$ & $16(3.49)$ & .11 \\
Stroke & & & \\
$\quad$ No stroke & $4958(98.84)$ & $439(95.64)$ & $<.001$ \\
$\quad$ Hemorrhagic stroke & $1(0.02)$ & $1(0.22)$ & \\
$\quad$ Embolic or ischemic stroke & $28(0.56)$ & $15(3.27)$ & \\
$\quad$ Undetermined stroke & $29(0.58)$ & $4(0.87)$ & \\
Transient ischemic attack & $21(0.42)$ & $3(0.65)$ & .47 \\
\hline Sepsis & $40(0.80)$ & $5(1.09)$ & .51 \\
Superficial wound infection & $60(1.20)$ & $6(1.31)$ & .83 \\
\hline
\end{tabular}

$s C A S$, Severe carotid artery disease. 


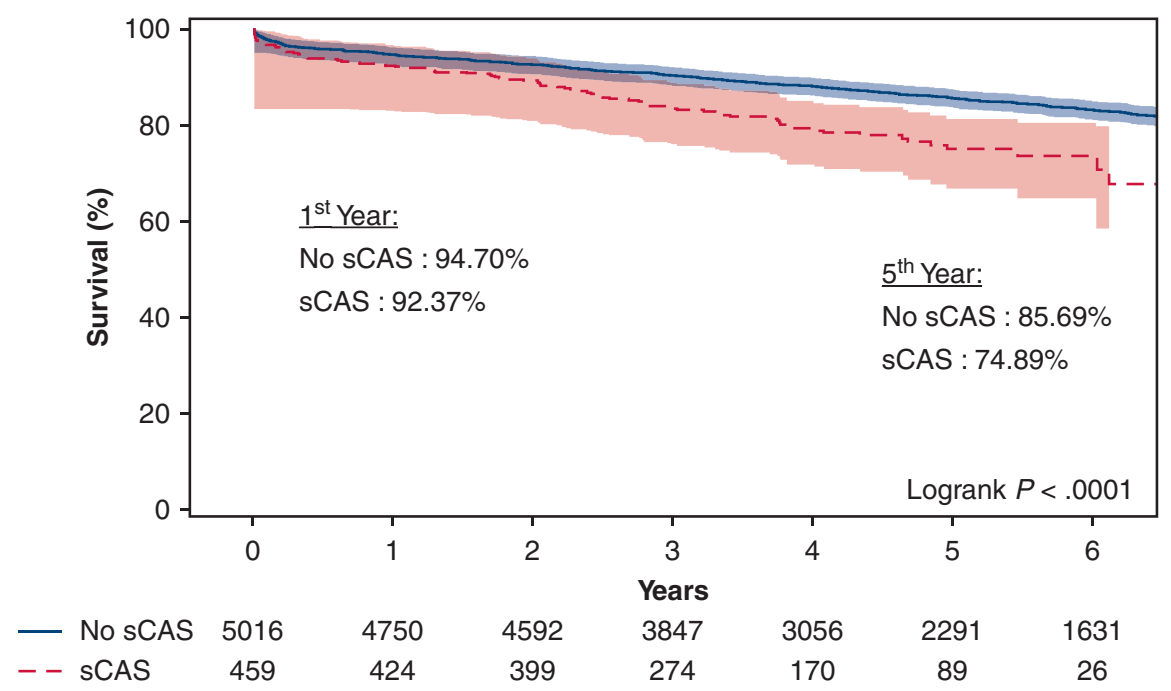

FIGURE 1. Kaplan-Meier survival following coronary artery bypass grafting in patients with and without severe carotid artery stenosis ( $s C A S)$. Patients with preexisting carotid stenosis at time of cardiac surgery were found to have reduced 5-year actuarial survival. The shaded band represents $95 \%$ confidence interval.

with long-term functional outcomes following stroke $(P=.334)$.

A total of 356 patients (300 without sCAS, 56 with sCAS) in this cohort had a history of previous cerebrovascular accident (CVA). Among patients without sCAS, the rate of postoperative stroke was higher in patients with prior CVA $(2.67 \%[\mathrm{n}=8]$ vs $1.06 \%[\mathrm{n}=150]$; $P=.02$ ) compared with those without prior CVA. The rate of stroke among patients with sCAS was highest in those with prior CVA, although the difference did not reach statistical significance $(4.22 \%[\mathrm{n}=17]$ vs $5.36 \%$ $[\mathrm{n}=3] ; P=.69)$.

\section{Postoperative Survival}

At both 1 year and 5 years, all-cause mortality was greater in the sCAS cohort $(7.63 \%$ vs $5.30 \%[P=.04]$ and $19.61 \%$ vs $12.70 \% \quad[P<.001]$, respectively) (Figure 1). On multivariable analysis, significant sCAS was a significant risk-adjusted predictor for mortality following CABG (hazard ratio [HR], 1.28; 95\% confidence interval $[\mathrm{CI}], 1.02-1.60 ; P=.030)$. Additional risk-adjusted predictors for mortality were identified, including increasing age, body mass index, and preoperative serum creatinine, as well as preoperative characteristics of diabetes mellitus, dialysis dependency, chronic obstructive pulmonary disease, immunosuppression, congestive heart failure, peripheral arterial disease, and history of prior CVA. Risk-adjusted predictors of a decreased hazard for mortality included increasing serum total albumin, increasing preoperative left ventricular ejection fraction, and, with initial presentation, acute coronary syndrome (unstable angina, non-ST elevation myocardial infarction, and/ or ST elevation myocardial infarction) (Table 3).

\section{Long-Term Readmission and Stroke}

The median duration of follow-up was 4.56 years (IQR, 3.02-6.45 years). Freedom from all-cause readmission was greater in the cohort without sCAS $(53.13 \%$ vs $42.92 \%, P<.001)$. Overall rate of stroke was also lower in the cohort without sCAS $(4.09 \%$ vs $7.19 \%, P<.001)$ (Figures 2 and 3).

Multivariable competing risk analysis was performed to identify risk-adjusted predictors for postoperative stroke. In this model, presence of sCAS was associated in increased hazards for stroke (HR 1.76, CI 95\% 1.20-2.59, $P=.004$ ). Other risk-adjusted predictors for stroke were history of prior CVA (HR 2.51, CI 95\% 1.77-3.55, $P<.001$ ), diabetes mellitus (HR 1.58, CI 95\% 1.21-2.08, $P=.001$ ), and black race (HR 1.94, CI 95\% 1.24-3.02, $P=.004$ ). There were no risk-adjusted predictors for reduced risk for stroke identified in this model (Table 4).

\section{Sub-Analysis: Intraoperative Hemodynamics}

Intraoperative blood pressures were available for 4962 patients, $4510(89.9 \%)$ without sCAS and $452(98.5 \%)$ with sCAS. Patients with sCAS had both a significantly lower median intraoperative MAP $(71 \mathrm{~mm} \mathrm{Hg}$ [IQR, 66$75 \mathrm{~mm} \mathrm{Hg}$ ] vs $72 \mathrm{~mm} \mathrm{Hg}$ [IQR, 68-77 $\mathrm{mm} \mathrm{Hg}$; $P<.001)$, as well as the lowest recorded intraoperative MAP (29 mm Hg [IQR, 12-38 mm Hg] vs $31 \mathrm{~mm} \mathrm{Hg}$ [IQR, 16-40 mm Hg]; $P=.005)$ compared with those without sCAS. However, the lowest intraoperative and median MAP did not differ between patients who experienced postoperative stroke and those who did not. Finally, modeled as a continuous univariable, neither median MAP (per $1 \mathrm{~mm} \mathrm{Hg}$; odds ratio, 0.98; 95\% CI, 0.95-1.01; $P=.14$ ) or lowest MAP (per $1 \mathrm{~mm} \mathrm{Hg}$; odds ratio 
TABLE 3. Cox proportional hazards model for postoperative mortality following CABG

\begin{tabular}{|c|c|c|}
\hline Variable & HR $(95 \%$ CI $)$ & $P$ value \\
\hline sCAS & $1.28(1.02-1.60)$ & .030 \\
\hline Diabetes mellitus & $1.36(1.18-1.56)$ & $<.001$ \\
\hline Dialysis dependency & $2.28(1.54-3.36)$ & $<.001$ \\
\hline $\begin{array}{l}\text { Chronic obstructive pulmonary } \\
\text { disease }\end{array}$ & $1.49(1.29-1.73)$ & $<.001$ \\
\hline Immunosuppression & $1.83(1.44-2.34)$ & $<.001$ \\
\hline $\begin{array}{l}\text { History of cerebrovascular } \\
\text { accident }\end{array}$ & $1.67(1.37-2.04)$ & $<.001$ \\
\hline Peripheral vascular disease & $1.71(1.48-1.98)$ & $<.001$ \\
\hline Previous myocardial infarction & $1.17(0.98-1.40)$ & .092 \\
\hline \multicolumn{3}{|l|}{ Cardiac presentation } \\
\hline Asymptomatic & $\begin{array}{l}\text { Reference } \\
\text { (Reference) }\end{array}$ & Reference \\
\hline Symptoms unlikely ischemia & $1.12(0.48-2.61)$ & .797 \\
\hline Stable angina & $1.05(0.78-1.41)$ & .736 \\
\hline Unstable angina & $0.74(0.58-0.93)$ & .010 \\
\hline NSTEMI & $0.64(0.49-0.84)$ & .001 \\
\hline STEMI & $0.59(0.41-0.85)$ & .004 \\
\hline Symptoms equivalent to angina & $0.82(0.42-1.58)$ & .551 \\
\hline Other & $0.56(0.33-0.95)$ & .032 \\
\hline Congestive heart failure & $1.31(1.09-1.56)$ & .004 \\
\hline Preoperative antiplatelet & $0.84(0.66-1.08)$ & .184 \\
\hline Preoperative anticoagulation & $1.32(1.10-1.57)$ & .003 \\
\hline Intravenous inotropes & $1.56(1.05-2.31)$ & .028 \\
\hline $\begin{array}{l}\text { Intra-aortic balloon pump use } \\
\text { None }\end{array}$ & $\begin{array}{l}\text { Reference } \\
\text { (Reference) }\end{array}$ & Reference \\
\hline Preoperative & $1.05(0.80-1.39)$ & .716 \\
\hline Intraoperative & $2.82(1.96-4.08)$ & $<.001$ \\
\hline Postoperative & $10.27(6.42-16.44)$ & $<.001$ \\
\hline \multicolumn{3}{|l|}{ Operative status } \\
\hline Elective & $\begin{array}{l}\text { Reference } \\
\text { (Reference) }\end{array}$ & Reference \\
\hline Urgent & $0.91(0.74-1.13)$ & .401 \\
\hline Emergent & $1.32(0.94-1.86)$ & .108 \\
\hline $\begin{array}{l}\text { Bilateral internal mammary artery } \\
\text { harvest }\end{array}$ & $0.86(0.72-1.03)$ & .102 \\
\hline Age, increasing, $y$ & $1.04(1.03-1.05)$ & $<.001$ \\
\hline $\begin{array}{l}\text { Body mass index, increasing, } \\
\mathrm{kg} / \mathrm{m}^{2}\end{array}$ & $1.02(1.00-1.03)$ & .027 \\
\hline $\begin{array}{l}\text { Serum creatinine, increasing, } \\
\mathrm{mg} / \mathrm{dL}\end{array}$ & $1.07(1.01-1.14)$ & .016 \\
\hline Total albumin, increasing, $\mathrm{g} / \mathrm{dL}$ & $0.59(0.50-0.69)$ & $<.001$ \\
\hline $\begin{array}{l}\text { Left ventricular ejection fraction, } \\
\text { increasing, } \%\end{array}$ & $0.99(0.98-0.99)$ & $<.001$ \\
\hline
\end{tabular}

1.00; 95\% CI, 0.99-1.02; $P=.60)$ intraoperatively had a significant association with postoperative stroke.

\section{DISCUSSION}

The main finding of this study is that the incidence of postoperative stroke following $\mathrm{CABG}$ was $>3$-fold higher in patients with known sCAS compared with those without sCAS. The majority of these strokes had either an ischemic or embolic etiology. Five-year survival was significantly lower in patients with sCAS, and sCAS was found to be an independent predictor for increased hazards for both mortality and stroke in multivariable modeling. Although a strong predictor of stroke, less than one-half of strokes experienced in patients with sCAS had locations of distribution that may have been influenced by the carotid lesions. The strongest risk-adjusted predictor of postoperative stroke was a history of previous CVA.

The management of sCAS during CABG remains a challenge. Previous practices included simultaneous coronary and carotid revascularization; however, the results have been mostly discouraging. ${ }^{2,6,8}$ A recent systematic review by Giannopoulos and colleagues ${ }^{2}$ looked at experiences with synchronous carotid endarterectomy and CABG versus staged carotid stenting and $\mathrm{CABG}$. In review of several series, ${ }^{9-13}$ their meta-analysis revealed no differences in postoperative stroke, transient ischemic attack, or myocardial infarction. However, there were increased odds of mortality with synchronous procedures (OR, 1.80; 95\% CI, 1.05-3.06). ${ }^{2}$ Similarly, a meta-analysis by Borger and colleagues ${ }^{14}$ found an increased risk of a combined outcome of death or stroke (relative risk, 1.49; 95\% CI, 1.03-2.15) with combined carotid endarterectomy and CABG compared these procedures performed in a staged fashion. Conversely, other groups have reported series of concomitant carotid revascularization and cardiac surgery procedures, both coronary and noncoronary, with acceptable rates of postoperative mortality and stroke. ${ }^{15-17}$ However, a major limitation of the current literature is the retrospective nature of these studies and lack of randomized trials.

Owing to the potential increased risk of morbidity and/or mortality, the practice of synchronous procedures has been largely abandoned at our institution. We tend to focus on the more symptomatic lesion first, with staged intervention of other lesions at a later date. For example, in patients with transient ischemic attack or prior CVA and without acute coronary syndrome, we typically would address the carotid lesion first and then plan to perform CABG a few days later during the same admission. With this selective staged approach, we still found that the presence of sCAS had a significant association with stroke. However, the strongest predictor of postoperative stroke was a history of previous neurologic event. A history of prior CVA was found in $6.5 \%$ of our CABG population, with at least $91.9 \%$ of 


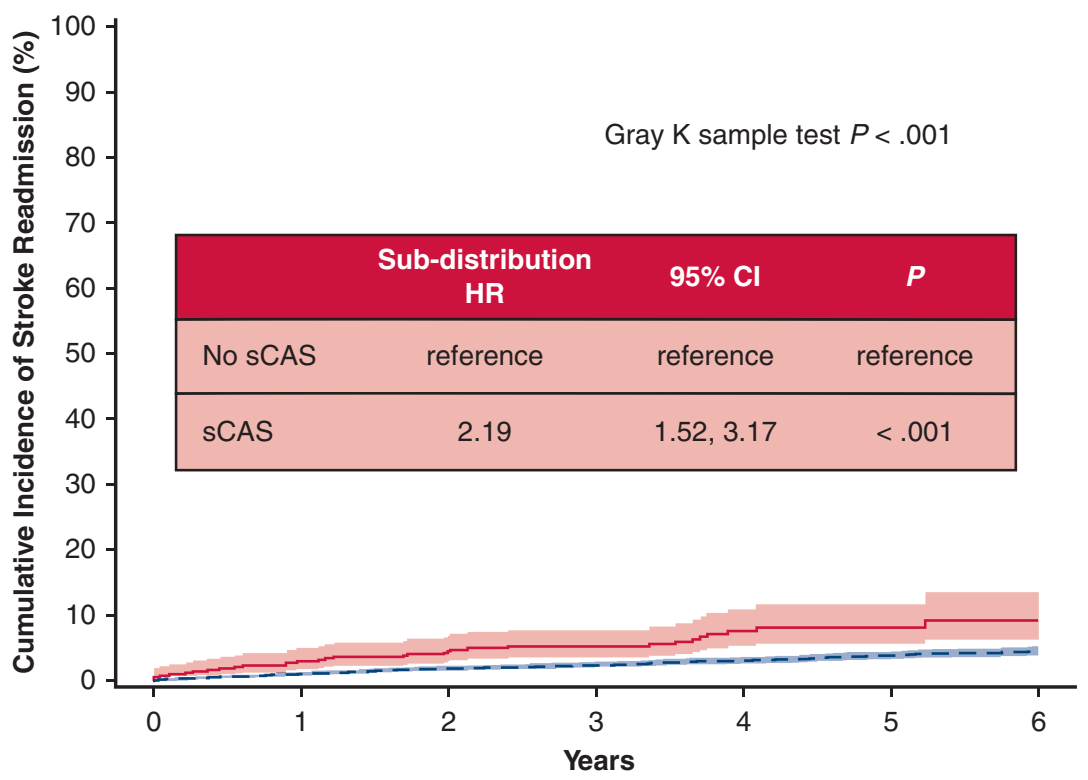

Patients-at-Risk

$\begin{array}{lccccccc}- \text { sCAS } & 459 & 411 & 380 & 259 & 155 & 81 & 23 \\ -- \text { No sCAS } & 5016 & 4705 & 4508 & 3758 & 2966 & 2202 & 1554\end{array}$

FIGURE 2. Competing incidence of stroke readmission following coronary artery bypass grafting in patients with and without severe carotid artery stenosis $(s C A S)$. In this analysis, death was the competing event. The shaded band represents $95 \%$ confidence interval $(C I)$. $H R$, Hazard ratio.

\section{What are the Impacts of Untreated Severe Carotid Artery Stenosis at Time of Coronary Artery Bypass Grafting?}

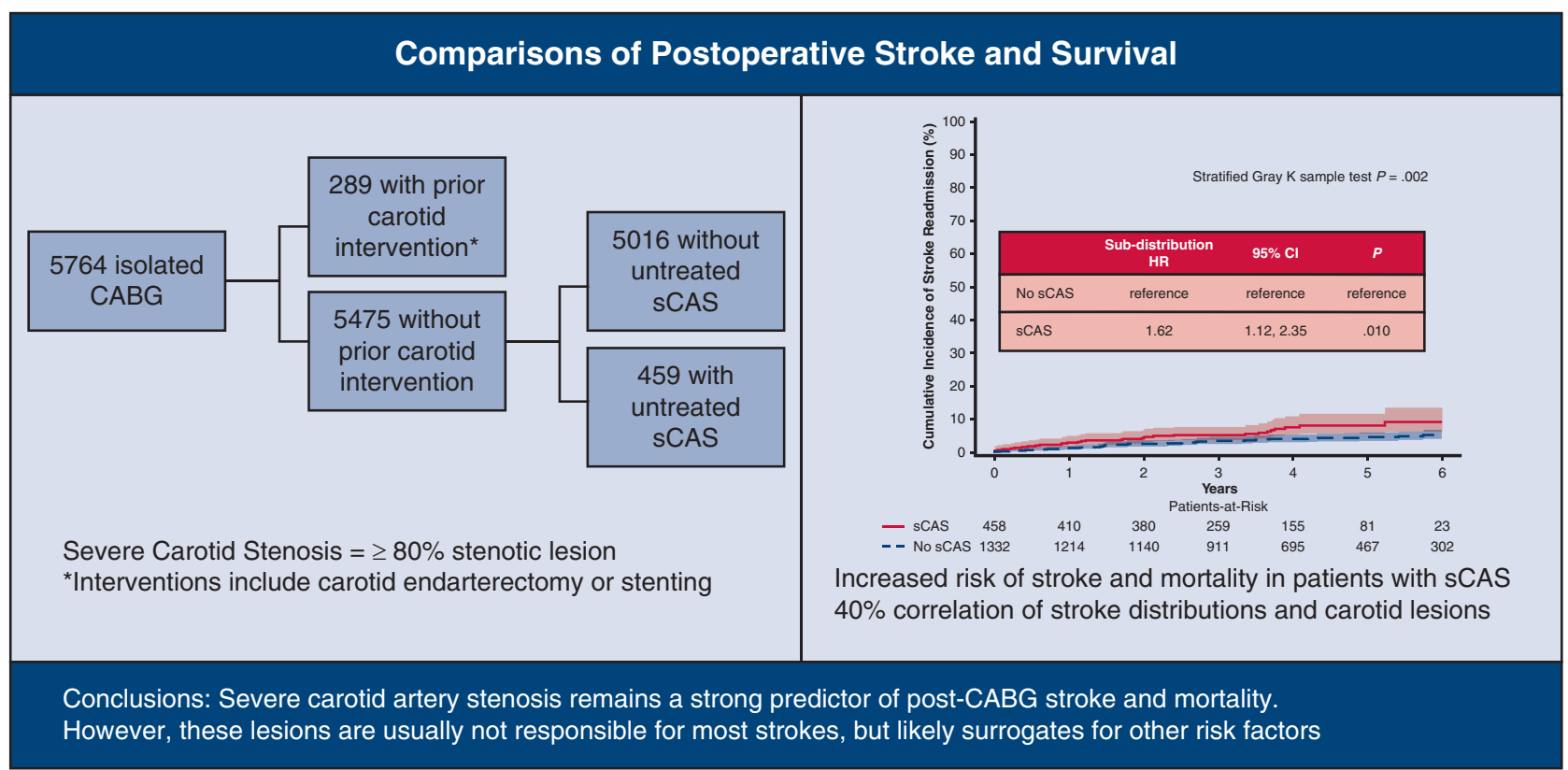

$\mathrm{CABG}=$ coronary artery bypass grafting; $\mathrm{SCAS}=$ severe carotid artery stenosis

FIGURE 3. In addition to a higher rate of postoperative stroke, patients with severe carotid artery stenosis $(s C A S)$ demonstrated significantly higher cumulative incidence of stroke readmission following coronary artery bypass grafting $(C A B G)$ surgery at 5 years. The shaded band represents $95 \%$ confidence interval $(C I)$. $H R$, Hazard ratio. 
TABLE 4. Competing risk analysis for stroke readmission by the Fine and Gray model, with death as a competing event

\begin{tabular}{|c|c|c|}
\hline Variable & HR $(95 \%$ CI $)$ & $P$ value \\
\hline sCAS & $1.76(1.20-2.59)$ & .004 \\
\hline $\begin{array}{l}\text { Left ventricular ejection fraction, } \\
\text { increasing, } \%\end{array}$ & $0.99(0.98-1.00)$ & .119 \\
\hline Total albumin, increasing, $\mathrm{g} / \mathrm{dL}$ & $0.88(0.66-1.18)$ & .386 \\
\hline Body mass index, increasing, $\mathrm{m}^{2}$ & $0.98(0.96-1.00)$ & .078 \\
\hline Age, increasing, $y$ & $1.01(1.00-1.03)$ & .073 \\
\hline \multicolumn{3}{|l|}{ Intra-aortic balloon pump usage } \\
\hline None & $\begin{array}{l}\text { Reference } \\
\text { (Reference) }\end{array}$ & Reference \\
\hline Preoperative & $0.58(0.31-1.09)$ & .090 \\
\hline Intraoperative & $0.63(0.20-2.01)$ & .433 \\
\hline Postoperative & NA (NA) & NA \\
\hline Congestive heart failure & $0.89(0.60-1.32)$ & .565 \\
\hline Previous myocardial infarction & $1.20(0.90-1.61)$ & .217 \\
\hline Peripheral vascular disease & $1.18(0.87-1.61)$ & .295 \\
\hline History of cerebrovascular accident & $2.51(1.77-3.55)$ & $<.001$ \\
\hline Immunosuppression & $1.59(0.99-2.56)$ & .057 \\
\hline $\begin{array}{l}\text { Chronic obstructive pulmonary } \\
\text { disease }\end{array}$ & $1.12(0.83-1.52)$ & .462 \\
\hline Diabetes mellitus & $1.58(1.21-2.08)$ & .001 \\
\hline \multicolumn{3}{|l|}{ Race } \\
\hline White & $\begin{array}{l}\text { Reference } \\
\text { (Reference) }\end{array}$ & Reference \\
\hline Black & $1.94(1.24-3.02)$ & .004 \\
\hline Other & $1.33(0.65-2.71)$ & .438 \\
\hline Female sex & $1.20(0.91-1.59)$ & .192 \\
\hline
\end{tabular}

$H R$, Hazard ratio; $C I$, confidence interval; $s C A S$, severe carotid artery disease; $N A$, not applicable.

the neurologic events occurring more than 2 weeks from the time of CABG, many longer than 1 month before CABG. Thus, the majority of patients were neurologically asymptomatic at the time of CABG. Although these patients were largely asymptomatic at time of surgery, prior CVA was associated with a higher rate of stroke in patients without sCAS $(1.06 \%$ vs $2.67 \%, P=.02)$, as well as in patients with sCAS $(4.22 \%$ vs $5.36 \%)$, although the difference did not reach statistical significance $(P=.69)$.

The intraoperative and postoperative management of patients with known carotid stenosis also remains a subject of debate. Most surgeons in our institutions would agree that intraoperative and postoperative blood pressures goals should be set higher in patients with sCAS to ensure adequate perfusion across these stenotic lesions. However, a review of our intraoperative records indicates that higher intraoperative blood pressure did not appear to be maintained in this subgroup. Although not clinically different, we found that median and lowest recorded MAPs were actually lower in the sCAS cohort. Though prolonged periods of hypotension may certainly induce global brain ischemia and anoxic events, we were not able detect a difference in median or lowest intraoperative MAP between patients who experienced a stroke and those who did not. Furthermore, the median and lowest MAP were not correlated with the outcome of stroke in a univariable analysis. Although intraoperative hemodynamic recordings may shed some light on the overall conduct of an operation, this retrospective review is not likely able to adequately quantify a patient's cumulative exposure to periods of hypoperfusion during CABG.

Interestingly, a study from Naylor and colleagues ${ }^{18}$ found poor correlation with postoperative stroke distribution and the presence of sCAS following CABG. In this study, only $50 \%$ of strokes occurred in patients with significant carotid disease, and more than $50 \%$ of strokes in patients with sCAS occurred in territories that could not be explained by their preexisting carotid disease alone. In our review, we found that only $40 \%$ of strokes occurring in patients with sCAS had an etiology and distribution that could possibly be explained by their carotid lesions. These findings suggest that perhaps sCAS often is not the etiology of stroke, but rather a surrogate for other unmeasured or often nonquantified risk factors, such as aortic calcification or atheroma. In a propensity-matched analysis, Cywinski and colleagues ${ }^{19}$ reported a similar stroke and mortality rate between patients undergoing combined CABG and carotid endarterectomy and those undergoing isolated CABG but with a history of prior carotid endarterectomy. Though stroke and mortality rates were similar between the groups, they were higher than those in a propensity-matched group of patients undergoing isolated CABG without a history of endarterectomy. Such findings suggest that prior carotid intervention may not necessarily mitigate stroke risk in this patient population.

\section{Study Implications}

This study demonstrates the complicated nature of sCAS surveillance in the routine preoperative workup for CABG. Although sCAS stands as a predictor for the occurrence of postoperative stroke, few strokes that occur can be attributed solely to these lesions. Moreover, whether preCABG carotid intervention may actually mitigate this increased risk of stroke is unclear. For these reasons, we do not advocate for routine carotid intervention prior to CABG in every patient with synchronous disease, especially in those without prior neurologic symptoms. At best, routine carotid ultrasound may serve as a tool for risk stratification and patient counseling before CABG, given that carotid disease is most likely a surrogate for other unmeasured risk factors. Patients may be counseled that existing carotid lesions may portend an elevated risk of stroke and reduced long-term survival, although intervening on these lesions before CABG might not actually impact this risk. Because routine carotid imaging is unlikely to impact the operative course in most patients, it may be reserved for 
higher-risk patient subsets, such as those with prior CVA, to identify symptomatic and possibly intervenable lesions before CABG.

\section{Limitations}

This study has several limitations. First, as a nonrandomized observational study, this may be subject to selection bias. To account for such bias between patient cohorts, we performed multivariable modeling to adjust for differences in baseline risk factors. However, it is possible that further unmeasured risk factors exist and may have influenced the study findings. In addition, all intraoperative blood recordings were analyzed to determine the lowest and median MAP of each operation. However, these pressure recordings are not always recorded at exact time intervals. Although helpful for understanding overall blood pressure control during these cases, this retrospective review of records is likely not able to accurately measure a patient's cumulative exposure to blood pressures inadequate for brain perfusion.

\section{CONCLUSIONS}

In this analysis of 5475 patients undergoing isolated CABG, patients with untreated sCAS at time of the operation experienced a 3-fold higher rate of postoperative stroke compared with those without sCAS. One-year and 5-year mortality rates were lower in patients with sCAS, and sCAS remained an independent predictor of both mortality and stroke after risk adjustment. Of all preoperative predictors, a history of previous CVA had the highest hazard for stroke following $\mathrm{CABG}$, and careful consideration should be given to this subpopulation of patients during evaluation for CABG. Given the low correlation between the location of stroke and carotid disease, it is unclear whether prior carotid revascularization can benefit these patients. Although a potential tool for risk stratification and prognostication, routine carotid imaging is unlikely to prevent the majority of strokes that occur.

\section{Conflict of Interest Statement}

I.S. receives institutional research support from Medtronic and AtriCure. A.K. serves on the medical advisory board for Medtronic. These affiliations do not create direct conflicts with the content of this manuscript. All other authors reported no conflicts of interest.

The Journal policy requires editors and reviewers to disclose conflicts of interest and to decline handling or reviewing manuscripts for which they may have a conflict of interest. The editors and reviewers of this article have no conflicts of interest.

\section{References}

1. Masabni K, Raza S, Blackstone EH, Gornik HL, Sabik JF III. Does preoperative carotid stenosis screening reduce perioperative stroke in patients undergoing coronary artery bypass grafting? J Thorac Cardiovasc Surg. 2015;149:1253-60.
2. Giannopoulos S, Texakalidis P, Charisis N, Jonnalagadda AK, Chaitidis N, Giannopoulos S, et al. Synchronous carotid endarterectomy and coronary artery bypass graft versus staged carotid artery stenting and coronary artery bypass graft for patients with concomitant severe coronary and carotid stenosis: a systematic review and meta-analysis. Ann Vasc Surg. 2020;62:463-73.e4.

3. Santarpino G, Nicolini F, De Feo M, Dalén M, Fischlein T, Perrotti A, et al. Prognostic impact of asymptomatic carotid artery stenosis in patients undergoing coronary artery bypass grafting. Eur J Vasc Endovasc Surg. 2018;56:741-8.

4. Borger MA, Ivanov J, Weisel RD, Rao V, Peniston CM. Stroke during coronary bypass surgery: principal role of cerebral macroemboli. Eur J Cardiothorac Surg. 2001; 19:627-32.

5. Borger MA, Fremes SE. Management of patients with concomitant coronary and carotid vascular disease. Semin Thorac Cardiovasc Surg. 2001;13:192-8.

6. Coyle KA, Gray BC, Smith RB III, Salam AA, Dodson TF, Chaikof EL, et al. Morbidity and mortality associated with carotid endarterectomy: effect of adjunctive coronary revascularization. Ann Vasc Surg. 1995;9:21-7.

7. Sultan I, Bianco V, Kilic A, Jovin T, Jadhav A, Jankowitz B, et al. Predictors and outcomes of ischemic stroke after cardiac surgery. Ann Thorac Surg. 2020;110: 448-56.

8. Tzoumas A, Giannopoulos S, Texakalidis P, Charisis N, Machinis T, Koullias GJ. Synchronous versus staged carotid endarterectomy and coronary artery bypass graft for patients with concomitant severe coronary and carotid artery stenosis: a systematic review and meta-analysis. Ann Vasc Surg. 2020; 63:427-38.e1.

9. Abbasi K, Araghi MF, Zafarghandi M, Karimi A, Ahmadi H, Marzban M, et al. Concomitant carotid endarterectomy and coronary artery bypass grafting versus staged carotid stenting followed by coronary artery bypass grafting. J Cardiovasc Surg (Torino). 2008;49:285-8.

10. Şaşkın H, Duzyol C, Ozcan KS, Aksoy R, Idiz M. Is carotid artery stenting an alternative to simultaneous carotid endarterectomy performed for carotid artery stenosis in patients undergoing isolated coronary bypass surgery? Heart Surg Forum. 2015;18:E211-8.

11. Ribichini F, Tomai F, Reimers B, Russo P, Borioni R, Spartà D, et al. Clinical outcome after endovascular, surgical or hybrid revascularisation in patients with combined carotid and coronary artery disease: the Finalised Research in ENDovascular Strategies Study Group (FRIENDS). EuroIntervention. 2010;6: 328-35.

12. Feldman DN, Swaminathan RV, Geleris JD, Okin P, Minutello RM, Krishnan U, et al. Comparison of trends and in-hospital outcomes of concurrent carotid artery revascularization and coronary artery bypass graft surgery: the United States experience 2004 to 2012. JACC Cardiovasc Interv. 2017;10: 286-98.

13. Ziada KM, Yadav JS, Mukherjee D, Lauer MS, Bhatt DL, Kapadia S, et al. Comparison of results of carotid stenting followed by open heart surgery versus combined carotid endarterectomy and open heart surgery (coronary bypass with or without another procedure). Am J Cardiol. 2005;96:519-23.

14. Borger MA, Fremes SE, Weisel RD, Cohen G, Rao V, Lindsay TF, et al. Coronary bypass and carotid endarterectomy: does a combined approach increase risk? A metaanalysis. Ann Thorac Surg. 1999;68:14-20; discussion 21.

15. Salehi Ravesh M, Rusch R, Friedrich C, Teickner C, Berndt R, Haneya A, et al. Impact of patientś age on short and long-term outcome after carotid endarterectomy and simultaneous coronary artery bypass grafting. J Cardiothorac Surg. 2019;14:109.

16. Chiariello L, Nardi P, Pellegrino A, Saitto G, Chiariello GA, Russo M, et al. Simultaneous carotid artery stenting and heart surgery: expanded experience of hybrid surgical procedures. Ann Thorac Surg. 2015;99:1291-7.

17. Minami K, Fukahara K, Boethig D, Bairaktaris A, Fritzsche D, Koerfer R. Longterm results of simultaneous carotid endarterectomy and myocardial revascularization with cardiopulmonary bypass used for both procedures. J Thorac Cardiovasc Surg. 2000;119(4 Pt 1):764-73.

18. Naylor AR, Mehta Z, Rothwell PM, Bell PRF. Carotid artery disease and stroke during coronary artery bypass: a critical review of the literature. Eur J Vasc Endovasc Surg. 2002;23:283-94.

19. Cywinski JB, Koch CG, Krajewski LP, Smedira N, Li L, Starr NJ. Increased risk associated with combined carotid endarterectomy and coronary artery bypass graft surgery: a propensity-matched comparison with isolated coronary artery bypass graft surgery. J Cardiothorac Vasc Anesth. 2006;20:796-802.

Key Words: carotid artery stenosis, coronary artery disease, coronary artery bypass grafting 